A Behavioral Analysis of Two Strategies to Eliminate Racial Bias in Police Use-of-Force

Mychal A. Machado ${ }^{1}$ and Ashley M. Lugo ${ }^{2}$

${ }^{1}$ Department of Psychology, University of Alaska Anchorage

${ }^{2}$ School of Behavior Analysis, Florida Institute of Technology 


\begin{abstract}
Structural racism is rooted in American social systems that were supposedly designed to promote our right to life, liberty, and the pursuit of happiness. Social systems like policing, for example, are built on a foundation of discriminatory practices designed to disenfranchise Black, Indigenous, and people of color (BIPOC). One of the most recent visible examples of raciallybiased policing is the excessive use-of-force by officers toward BIPOC. In response, advocates, policy makers, and researchers have sought solutions. Police use-of-force reforms such as BodyWorn Cameras (BWCs) and Implicit Bias Training (IBT) have become popular and are currently being applied in many police departments across the country. However, evidence supporting the effectiveness of these reform strategies to reduce use-of-force is mixed, and further evaluations are needed to understand why these strategies are purported to be an effective solution. The purpose of the current review is to ignite future empirical evaluations of use-of-force reform. Following a summary of the research conducted to date on BWCs and IBT, we will conclude with a brief discussion of how behavior analysts might improve and foster strategies that are efficacious. Our ultimate goal is to leave the reader with an understanding of where the data have taken us thus far, and how behavior analysts and others can contribute to the reduction and eradication of the discriminatory practices present in policing and other social systems.
\end{abstract}

Keywords: use-of-force, body-worn cameras, implicit bias training, police brutality, racial bias 
This manuscript is being published on an expedited basis, as part of a series of emergency publications designed to help practitioners of applied behavior analysis take immediate action to address police brutality and systemic racism. The journal would like to especially thank Worner Leland and Dr. Natalie Parks for their insightful and expeditious reviews of this manuscript. The views and strategies suggested by the articles in this series do not represent the positions of the Association for Behavior Analysis, International or Springer Nature.

Guest Editor, Denisha Gingles 


\section{A Behavioral Analysis of Two Strategies to Eliminate Racial Bias in Police Use-of-Force}

"Prejudice is a burden that confuses the past, threatens the future, and renders the present inaccessible.” - Maya Angelou (1986, p. 155).

Prejudice has played a central role in American history, and the threat of its continuation into the future is clear. At present, we are in a place where the basic freedoms supposedly afforded to all are blocked through the systematic oppression of Black, Indigenous, and people of color (BIPOC). Prejudice is not the burden of any one person or group. Rather, prejudice is a social problem that envelops cities, countries, and continents. It impacts the world. Khanh Dinh, the noted social justice advocate, has asserted that prejudice is a social pollution, which affects everyone within a society (Seitz, 2011). There is no question to us that our country is metaphorically polluted. The air is thick with prejudice, breeding attitudes and biases that further the separation of humans from their inalienable rights. It is no wonder people say they cannot breathe.

In order to begin to rectify the centuries-long injustices that have polluted the lives of BIPOC, we must identify the specific harmful practices that poison their livelihood. Social systems like policing pose a direct threat to BIPOC's lives. One of the most dangerous and recently visible examples is the excessive use-of-force by officers toward BIPOC (Bosman \& Smith, 2017; Hickman \& Poore, 2016; Legwie, 2016; Lum \& Nagin, 2017; Marcus, 2016; Nix et al., 2017; Smith, 2017; Zimrig, 2017). To be clear, officers have the right to use reasonable force, even deadly force, when necessary (Fridell, 2005), but the term reasonable has been continuously defined (e.g., Morrozoff Luna, 2005) and applied (e.g., Terrill \& Paoline III, 2017) prejudicially across classes and races. In one of the first reviews of use-of-force, Black (1976) reported that BIPOC of all social classes were far more likely to contact force during interactions with officers than their white counterparts. The data available at the time also suggested that 
when deaths occurred during police interactions, BIPOC were more likely to be victims than white individuals, especially when unarmed. More recently, DeGue et al. (2016) and Nix et al. (2017) examined deaths involving police officers reported from facilities across the United States. DeGue et al. reported that $89 \%$ of the 812 incidents reviewed involved a BIPOC victim, and $86 \%$ of BIPOC victims were shot fatally while unarmed. Nix et al. found similar results with around $50 \%$ of the 990 incidents reviewed involving a BIPOC victim. Sixty-six percent of those victims were also shot while unarmed. Together, these data support a phenomenon suspected to exist long before data were available for verification: Officers use excessive use-of-force toward BIPOC. In response, advocates, policy makers, and researchers continue to seek solutions. The most common approach to improving use-of-force toward BIPOC by police officers has been to optimize use-of-force through executive policies in an effort to protect all citizens (University of Chicago Law School - International Human Rights Clinic, 2020). Current solutions under this umbrella involve police use-of-force reforms such as Body-Worn Cameras (BWCs) and Implicit Bias Training (IBT). Since 2014, these strategies have become popular and have been applied in many police departments across the country (Attard, 2010; Mears et al. 2017; Yokum et al., 2019). However, evidence supporting the effectiveness of these reform strategies is mixed, and further evaluations are needed to understand why these strategies are purported to be an effective solution. Moreover, a noted gap in the available literature is the absence of a behavior analytic point-of-view (cf. De Houwer, 2019), which has the potential to expand our knowledge of the relevant variables responsible for behavior change when observed. We strongly believe that bringing behavior analysts into the conversation about racially-biased policing and the excessive use-of-force can help meet these optimization goals. 
The purpose of the current review is to ignite future empirical evaluations of use-of-force reform. Following a summary of the research conducted to date on BWCs and IBT, we will conclude with a brief discussion of how behavior analysts might improve and foster strategies in these areas that are efficacious. Our ultimate goal is to leave the reader with an understanding of where the data have taken us thus far, and how behavior analysts and others can contribute to the eradication of discriminatory practices in policing and other social systems.

\section{Police Use-of-Force Reform: Two Strategies}

\section{Strategy \#1: Body-Worn Cameras (BWCs)}

\section{Expected Effects and Background}

BWCs are cameras affixed to an officer's head or chest area used to record interactions between officers and citizens. Since 2015, the US Department of Justice has awarded millions in funding to support the implementation of BWC programs, and the number of police departments using BWCs has continued to rise (Murphy, 2019). A major factor contributing to this quick support and adoption is the expectation of certain behavioral effects. Specifically, BWCs are intended to deter officers' unjustified use-of-force and civilian physical resistance during police encounters, which is expected to facilitate a positive shift in the public's stated perception of police legitimacy (Chapman, 2019). The accumulated video records are also expected to resolve citizen complaints and assist in the design of use-of-force training programs. A purported secondary effect is a reduction in use-of-force toward BIPOC, because BWCs are expected to promote impartial policing strategies focused on the safety of all citizens, regardless of race (Murphy, 2019).

Recommendations to adopt BWCs have significantly outpaced research evaluating the expected effects. The research conducted thus far has often been narrow in scope and has failed 
to address some of the major claims used to promote BWC programs. Recently, Lum et al. (2019) examined the results from 70 empirical studies in the largest systematic review of BWC research to date (see Lum et al., 2019 for a complete list of studies). The review focused on three primary dependent variables: changes in officer and citizen behavior, officer attitudes toward BWCs, and citizen ratings of police legitimacy. Officer and citizen behavior were defined by the number of citizen complaints involving use-of-force and officer reports involving combative resistance-to-arrest, respectively. Officer attitudes were defined by ratings of satisfaction using BWCs, and perceptions of legitimacy were defined by ratings of willingness to comply and interact with police officers. Research designs varied in strength.

Lum et al. (2019) found studies that relied on data accrued after BWCs were introduced (i.e., posttest-only designs) demonstrated the most compelling support for the expected effects of BWCs, particularly with respect to the number of use-of-force complaints (e.g., Ellis et al., 2015; Gaub et al., 2016) and the number of reports involving combative behavior during arrest (e.g., Hedberg et al., 2017). Some evidence for improved perceptions of legitimacy (e.g., Lum et al., 2015) were also reported, but this finding was not consistent across evaluations (Miller et al., 2014). Similarly, pretest-posttest evaluations and randomized controlled trials (RCTs) produced mixed results in terms of effectiveness overall. Some evaluations reported significant reductions in use-of-force complaints (e.g., Braga et al., 2018), improvements in officer attitudes toward BWCs (e.g., Gaub et al., 2016), and citizen compliance with officer requests following the introduction of BWCs (e.g., Jennings et al., 2017). In contrast, other studies demonstrated the opposite outcomes or no effect at all (e.g., Ariel et al., 2016a; Ariel et al., 2016b; Goodall, 2007; Grossmith et al., 2015; Yokum et al., 2019). Together, the data reviewed by Lum et al. (2019) suggest there is a mix of positive, null, and negative support for BWCs. Similar findings have 
been reported in other, smaller-scale reviews of BWCs (i.e., Ariel et al., 2017; Cubitt et al., 2017; Jennings et al., 2017; Miller et al., 2014), which suggests evidence demonstrating the expected effects has been inconsistent.

\section{Limitations and Future Directions}

A potential explanation for mixed outcomes could be that additional treatment components were present in some but not all evaluations of BWCs. For example, supporters of BWCs suggest that observer effects underlie their effectiveness (Ariel et al., 2017), and in some studies officers were instructed to deliver a verbal warning to citizens when initiating recordings using BWCs (e.g., Katz et al., 2015; Lum et al., 2015; Miller et al., 2014). If observer effects truly underlie the effectiveness of BWCs, the presence of a verbal warning drawing attention to the camera is unlikely to be innocuous. That is, the presence of a verbal warning may amplify or independently explain the expected effects of BWCs. As another example, reductions in use-offorce in the presence of a BWC might be the combined product of rule governance and the BWC. If officers have experience following social or self-generated rules related to when and how to implement force, and these rules change in the presence of a BWC, then reductions in use-of-force are likely the product of both components. To address these possibilities, the presence and absence of verbal warnings and rules related to force should be evaluated systematically. These data might highlight whether BWCs produce their effects in isolation or in conjunction with other treatment components.

Another potential explanation for mixed outcomes could be tied to variations in fidelity following department policies related to BWCs. For example, departments have individualized policies around the use of BWCs (Murphy, 2019), but procedures related to activation during an encounter have largely been left to each officer's discretion or based on a broadly defined rule 
(Lum et al., 2019). Similarly, the specific instructions given to officers related to verbal warnings are unclear in most cases. When authors have noted the specific use of instructions related to BWC activation and verbal warnings, the procedural details were vague and measures of fidelity were never reported (e.g., Ariel et al., 2017; Ariel et al., 2018). Thus, it remains unclear whether BWCs have been used with fidelity within and across a majority of departments and evaluations. To address these limitations, the fidelity with which cameras are activated and verbal warnings are implemented should be considered in future studies. These data might highlight how differences in treatment fidelity impact obtained outcomes.

In addition to evaluating variations in treatment components and the fidelity with which those components are implemented, future researchers might also evaluate the appropriateness of the dependent measures used in BWC research to determine changes in use-of-force. Use-offorce complaints and combat incident reports filed by citizens and officers, respectively, are the most commonly used measures of use-of-force in this area (Lum et al., 2019). Use-of-force complaints are formal reports completed by citizens with police departments indicating an officer used force toward a citizen during an interaction. Combat incident reports are formal reports filed within departments by officers indicating that a citizen used force toward an officer during an interaction. According to Murphy (2019), these proxy measures might significantly over- or underrepresent these behaviors, because additional variables might change motivation to file a complaint or report. For example, the response effort associated with filing a complaint or report might mitigate motivation to complete the complaint or report if that effort is too high for the officer, citizen, or both (Chapman, 2019). As another example, Terrill and Paoline III (2017) suggested BIPOC victims of force are potentially less motivated to file a complaint against a white officer, especially if there is a suspected fear of retaliation or a lack of faith in the 
accountability process. In response, departments using BWCs might consider more objective measures in lieu of or as a substitute to citizen complaints and officer reports. Departments may, for example, review samples of recorded video, score use-of-force and combative behavior independently, and then use those data as a supplement to or verification of citizen complaints and officer reports. These data would potentially highlight issues in use-of-force and resistanceto-arrest reporting fidelity, and allow the examination of variables that produce discrepancies when they occur.

Claims not yet tested should also be addressed. We are unaware of any specific evaluations that have targeted the efficiency of resolving citizen complaints or whether training programs designed using BWCs produce reductions in use-of-force. Potentially more problematic, we found a lack of empirical articles addressing whether BWCs directly influence racially-biased policing. These latter data are critical, because officers have been shown to disproportionately apply excessive use-of-force toward BIPOC (Nix et al., 2017), and proponents of BWCs have claimed that BWC usage could successfully ameliorate these discrepancies (Chapman, 2019). Future research on these untested claims will therefore be necessary to determine if all claimed effects of BWCs are substantiated.

\section{Room for Behavior Analysts}

Psychologists, criminologists, sociologists, lawyers, and law enforcement agencies have weighed in on the effectiveness of BWCs (Lum et al., 2019). A noted gap is the absence of a behavior analytic point-of-view, which can offer an analysis of the relevant variables responsible for behavior change that are associated with the implementation of BWC programs.

BWCs as Antecedent Manipulations. From a behavior analytic perspective, organisms that do not readily respond in a desired manner under specific conditions typically lack the 
required learning history or are in a position where the current environment does not evoke or support such behavior, and both issues can be addressed (Skinner, 1953). Many aspects of the environment can acquire stimulus control over behavior or serve as motivating operations.

Stimulus control occurs as the result of pairing people, places, and things (i.e., antecedents) with specific consequences (Luiselli et al., 2008). Motivating operations impact the value of a particular consequence and the momentary frequency of all behavior that have resulted in that consequence historically (Michael, 1993). In a policing context, BWCs could be conceptualized as an antecedent strategy that should evoke socially congruent behaviors (e.g., covert rules or overt behavior), potentiate the value of escape from punitive consequences, or both. In this way, departments might consider ways to establish BWCs as effective antecedents when shown to be ineffective. A potential method for meeting this goal could be pairing consistent, quick, and appropriate contingencies with BWCs. Contact with these contingencies could subsequently aid in the establishment of rules that govern future professional behavior in the presence of BWCs.

BWCs as a Method to Determine Consequences. Research (e.g., Ariel et al., 2017) and conceptual analyses (e.g., Chapman, 2019) have suggested correlations between perceptions of police legitimacy and accountability. Based on these data and analyses, it is often assumed that when officers are held accountable for use-of-force or view others being held accountable they are more likely to act professionally in the future. Ariel et al. (2017) refers to this phenomenon as “contagious accountability.” Although conceptually reasonable from a behavior analytic standpoint, to date, the use of BWCs as a strategy to determine consequences has been limited to citizen prosecution (Lum et al., 2019). The role of BWCs in officer accountability has not been reported, which provides a unique opportunity for behavior analysts who rely on arranged consequences to establish and maintain behavior change. 
Conceptually, BWCs create a permanent product of encounters, which could be used to determine specific consequences aimed at reducing and establishing certain behaviors. Following observations of someone contacting or directly contacting those consequences, BWCs might then become discriminative (i.e., an effective antecedent) for professional behavior and compliance. However, the immediacy and consistency of a consequence plays a pivotal role in behavior change (see Skinner, 1953 and Skinner, 1969 for seminal texts), and legal reports suggest that consequences for use-of-force are often absent or delayed significantly (e.g., University of Chicago Law School - International Human Rights Clinic, 2020). In response, researchers and department supervisors could use live-feed BWCs to identify use-of-force during an encounter and intervene immediately. If live observation is impractical, videos could be viewed after capture to identify use-of-force and then reviewed with officers during the accountability process as visual models of unprofessional behavior. Program evaluators could then examine the efficacy of those programmed consequences over time.

BWCs as a Tool in the Development of Training Programs. It is often assumed that when officers are trained well, use-of-force and other unprofessional behavior (e.g., unsubstantiated traffic stops) will decrease in the future, which improves perceptions of legitimacy (Murphy, 2019). In this way, Murphy (2019) suggested that BWCs might allow departments to develop effective training programs to reduce officers' use-of-force, especially toward BIPOC. This claim has not been evaluated, and many departments have reported variations in BWC and use-of-force training procedures (Katz et al., 2015; Lafayette Group, 2015; Lum et al., 2015; Miller et al., 2014). Generally, procedures for both skills have relied heavily on didactic information through the presentation of written and visual materials. From a behavior analytic perspective, this is an effective strategy for promoting verbal behavior 
surrounding a topic. To establish specific skills (e.g., recording properly and exhausting all reasonable alternatives prior to force), performance- and competency-based strategies (see Reid et al., 2003) will likely be more effective. Departments might therefore evaluate how evidencedbased skills training techniques, such as behavioral coaching (e.g., Rodriguez et al., 2009), behavioral skills training (e.g., Parsons et al., 2012), and video modeling (e.g., DiGennaro Reed et al., 2019) could be used to promote appropriate use of BWCs and reductions in use-of-force.

\section{Strategy \#2: Implicit Bias Training}

\section{Expected Effects and Background}

Like BWCs, Implicit Bias Training (IBT) has been lauded as an evidence-based solution to resolve excessive use-of-force toward BIPOC (Department of Justice Community Relations Services Toolkit for Policing, n.d.). The objective of IBT is to draw awareness to and replace implicit biases that police officers may have against-marginalized groups. IBT is based on the premise that while an individual may not exhibit explicit (i.e., overt) bias, they may still be influenced by implicit (i.e., unconscious) biases. Researchers have posited that if implicit biases can be modified via intervention, explicit measures and behaviors influenced by those biases will, in turn, follow (Forscher et al., 2019). IBT is therefore broadly defined as any procedure implemented with the specific objective of changing implicit biases (Forscher et al., 2019).

Implicit bias has been defined within psychology as "unconscious prejudice that people may develop due to differential life experiences" (Engel et al., 2020 p. 156). Functionally, implicit biases can be operationally defined as "behavior that is influenced in an implicit manner by cues that function as an indicator of the social group to which others belong" (De Houwer, 2019, p. 835). These biases can evoke discriminatory behaviors in policing and are separated into three categories: general trait and behavioral biases, specific race-crime biases, and race-weapon 
biases (Spencer et al., 2016). General trait and behavioral biases consist of scenarios in which an officer identifies the ambiguous behavior of a BIPOC as aggressive, even if the behaviors exhibited by BIPOC and white individuals are identical (Duncan, 1976; Sagar \& Schofield, 1980). Race-crime biases consist of associating BIPOC with behavior that violates the law. An officer may scan for criminal activity in the community and specifically target BIPOC (Eberhardt et al., 2004). Race-weapon bias is an assumption that BIPOC are in possession of a weapon. This bias has been found to predict shooter bias in first-person shooter tests (e.g., Correll et al., 2007). Together, these implicit biases are suggested to profoundly impact the extent to which BIPOC are policed, including the extent to which use-of-force is implemented during encounters. IBT is claimed to specifically target and treat these biases.

IBT has historically included several variations of training, including (a) stereotype replacement, (b) counter-stereotypic imaging, (c) individuation, (d) perspective taking, and (e) increased opportunities for contact. Stereotype replacement involves teaching individuals to recognize their own stereotyped responses and then consider alternative responses to replace those stereotyped responses (Department of Justice, n.d.). Counter-stereotypic imaging involves teaching individuals to recognize their response as stereotyped, and then recall personal examples that are incompatible with those stereotypes (Spencer et al., 2016). Individuation involves teaching individuals to associate characteristics to singular people rather than the groups with which they identify (Department of Justice, n.d.). Perspective-taking interventions teach officers to empathize with others and understand how their own biases may affect the individuals they police (Spencer et al., 2016). Lastly, interventions targeting increases in opportunities for contact systematically arrange situations where officers can contact stereotyped groups in situations unassociated with the stereotyped behaviors. Whether used individually or in 
conjunction, these strategies are expected to reduce a variety of implicit biases that can underlie racially-biased behavior, including the use-of-force toward BIPOC.

Changes in implicit bias during IBT are measured through the Implicit Association Test (IAT), which is often administered via computer software programs (Greenwald et al., 1998.). Typically, the IAT involves five stages. In Stages 1 and 2, participants are instructed to sort words or pictures into categories relating to the target concept (e.g., skin color) and then the construct (e.g., safety) being measured. For example, participants might first sort pictures of people with black and white skin by selecting corresponding keys on the keyboard and then sort a different stimulus set (e.g., pictures of weapons and non-weapons) into categories such as “dangerous" and "safe." In Stages 3 and 4, categories and concepts are combined such that one category and concept combination is randomized to each side of the screen (i.e., "Black people/dangerous" on left and "white people/safe" on right); these combinations are then counterbalanced via alternating sides of the screen. In Stage 5, the combinations of concept and construct are rearranged (i.e., Black people/safe, white people/dangerous). The primary dependent variable is the difference in response latency across the sorting tasks in Stages 3 and 5. If response latency varies across stages significantly, implicit bias is hypothesized to be present. Studies that use the IAT can also include secondary dependent variables such as explicit measures including the frequency of errors and correct responses emitted during the IAT, responses on questionnaires that measure the phenomenon of interest, or observable behavior (e.g., engagement with peers of various ethnicities).

The IAT has been used to measure various police behaviors within highly controlled experimental laboratory arrangements. Using a variation of the IAT arrangement, Correll et al. (2002) developed the first-person shooter task designed to simulate scenarios police may 
encounter. A target (e.g., a Black or white male) is presented in front of a realistic background holding a weapon or a non-dangerous item, and participants were instructed to select "shoot" or “don't shoot" using the keyboard. The dependent measures were latency to respond and errors. Results showed that participants selected "shoot" more quickly (i.e., shorter latency) in the presence of Black targets, and they also depressed the "don't shoot" button more quickly in the presence of white targets. Participants were also more likely to erroneously shoot unarmed Black targets. A meta-analysis conducted by Mekawi and Bresin (2015) of 42 studies measuring laboratory arrangements of shooter bias further corroborate these findings.

More broadly, Oswald et al. (2013) conducted a meta-analysis examining the correlation between IAT measures and explicit measures of racial and ethnic discrimination. The evaluation aimed to assess whether the IAT could predict discrimination in real-world settings. The metaanalysis included 46 reports since 2006 . The IAT was tested for predictive validity related to criterion categories of implicit measures of discrimination (i.e., interpersonal behavior, person perception, policy preference, microbehavior, response time, and brain activity) and directly compared to measures of explicit bias (i.e., feeling thermometers, Modern Racism Scale, attitudes and stereotypes). Results from the meta-analysis indicated that the IAT was not a valid predictor of implicit measures, nor did it perform any better than explicit measures of bias like the Modern Racism Scale. The findings from this study suggested there is limited evidence to support a relation between implicit bias and behavior, and Oswald et al. (2013) is among a plurality of meta-analyses and systematic reviews reporting "a relatively narrow range of correlations between explicit and implicit measures of racial bias" (Hehman et al., 2019, p 1024).

If the IAT functions as proponents claim, then it would detect problematic implicit biases that necessitate interventions like IBT to target the reduction of the biases detected. Forscher et 
al. (2019) were the first to conduct a large-scale meta-analysis of procedures to change implicit bias, and the analysis consisted of 492 studies that employed various interventions. In brief, the findings suggested the type of procedure employed differentially impacted changes in implicit measures (e.g., reaction time during the test). The most promising procedures were ones that aimed directly to strengthen or weaken responses observed in the IAT itself, meaning that interventions targeting the specific relations assessed in the IAT led to more robust outcomes. However, across all interventions targeting implicit bias, the effect sizes were small or indistinguishable from zero, and evidence to support changes in implicit bias mediating changes in explicit behavior was not found. Together, these data suggest that even if the IAT can identify implicit biases, current IBT strategies to treat these biases are unlikely to be effective in an observerable (explicit) way.

\section{Limitations and Future Directions}

One of the most notable limitations of IBT is the use of the IAT as the primary dependent measure before and after training. If an IAT is a valid measure that detects an implicit bias, other measures (e.g., explicit bias measures) should indicate the same findings. There is no evidence thus far that indicates individuals are unaware of the biases they harbor (Gawronski, 2019). Moreover, there is speculation regarding the reliability of the IAT itself. Longitudinal studies using the IAT have found it a less stable measure compared to explicit behaviors (e.g., Cunningham et al., 2001). This is also evident in research measuring police bias specifically. For example, officers' implicit racial biases were found to vary widely across administrations of the test and to be correlated with external factors such as sleep deprivation (James, 2018). Based on these documented flaws in reliability, any IBT programs that use the IAT cannot exclusively rely 
on the outcomes it produces to indicate change, because the values tend to be variable even in the absence of intervention (Gawronksi, 2019; Oswald et al., 2013).

Additionally, the IAT's predictive validity has come under scrutiny. Meta-analyses and data re-evaluations indicate that the IAT does not reliably predict explicit bias or biased behaviors (e.g., Blanton et al., 2009; Oswald, 2013). If the primary dependent measures of bias are extrapolated from the IAT, the data must be correlated with meaningful outcomes. Currently, there is no evidence that the IAT produces valid measures to detect change in said outcomes. Skeptics of the IAT have even called for the dismissal of its use when seeking to understand and measure social discrimination in general (Blanton \& Jaccard, 2017; Mitchell, 2018). Nonetheless, the IAT's popularity has endured (Brownstein et al., 2019; Paluck \& Green, 2009). In addition to measurement concerns, the specific procedures included in IBT have also been met with speculation. Sourcing information from Paluck and Green (2009), Spencer et al., (2016) stated, "Many police departments engage in training to reduce bias, but, as is the case with 'diversity' and 'cultural sensitivity' training in other industries, there is no basis for confidence that these programs have meaningful, lasting effects" (p. 55). Most recently, Forscher et al., (2019) concluded that practitioners who aim to ameliorate problems that are presumed to be caused by implicit biases cannot rely on current IBT interventions to change implicit measures, because they do not consistently change explicit (overt) behavior. Furthermore, the least robust IBT outcomes have been produced from domains focused specifically on producing meaningful behavior change (e.g., intergroup bias, health psychology, and clinical psychology). Thus, it is unlikely that increasing awareness of the implicit biases officers may have towards BIPOC is a sufficient means to ameliorate biased use-of-force, because previous evaluations of IBT have failed to produce these data (Forscher et al., 2019; Spencer et al., 2016). 
Lastly, the assumption that knowledge gained from IBT programs will result in a meaningful change in bias has similarities to other phenomena studied within policing. For example, knowledge-based programs aimed at teaching police officers to respond effectively with individuals demonstrating mental health concerns do not always result in reduced incident reports involving mental health cases (e.g., Scantlebury et al., 2017). Police departments should not presume that knowledge-based interventions are sufficient behavior-change methods given the grave consequences of police use-of-force. Moreover, like with BWCs (see above), knowledge-based programs are likely only to promote verbal behavior surrounding a topic rather than actual behavior change. Explicit evidenced-based skills training techniques, such as behavioral coaching (e.g., Rodriguez et al., 2009), behavioral skills training (e.g., Parsons et al., 2012), and video modeling (e.g., DiGennaro Reed et al., 2019) will likely be necessary to sufficiently and meaningfully address biased behavior in the field.

\section{Room for Behavior Analysts}

The current body of research does not demonstrate that implicit bias is the mediating variable responsible for explicitly-biased behavior or that IBT is a successful behavior change intervention. Although behavior analysts have been largely inactive in these areas, some researchers have begun to further refine and objectively measure implicit bias through the use of relational frame theory (RFT). For example, the Implicit Relational Assessment Procedure (IRAP; Barnes-Holmes et al., 2010) is similar to the IAT and involves instructing participants to respond to a label (e.g., "Pleasant") and target word (e.g., "Black") by selecting different response options (e.g., "Similar" or "Different"). Responses to the relation presented may not suggest implicit bias (i.e., responses in this arrangement are explicit), but other dependent variables may be included to create a more molecular analysis. Latency to respond to the relation 
presented, for instance, is a measure of relative strength of a response in the participant's repertoire (see Palmer, 2009 for a discussion). If a participant has a longer latency to respond to the relation described, then the response is not at strength in the individual's repertoire. A longer latency to respond would, in turn, suggest a bias.

The IRAP as a refinement of the IAT could potentially offer more valid and reliable measures of bias for use with IBT, but interventions targeting explicit biases and observable behaviors associated with those measures continue to be overlooked. Concerns about predictive validity also remain, because changes in implicit bias measured through the IAT or IRAP are not shown to be correlated with explicit bias or outcomes. Blanton and Jaccard (2017) suggest a first step to resolving these issues: measure observable behavior. Applied to policing, this solution would involve avoiding indirect variables in favor of measuring use-of-force itself as the primary dependent variable in future evaluations. Complaints and reports, for example, are quantifiable measures of inappropriate use-of-force, and these variables have been used as primary dependent measures in other interventions targeting the same phenomenon (see BWC section above). Future researchers could therefore look for ways to incorporate measures of observerable behaviors in evaluations of IBT. Where observable behaviors are lacking or difficult to conceptualize, behavior analysts might assist in defining, tracking, and intervening using welldefined classes of behavior under the umbrella of "bias", potentially assuaging the need for indirect measures.

Beyond measurement, the interventions currently available within the literature do not show meaningful change in behavioral outcomes, which suggests alternatives to IBT should be explored. Some behavior analytic procedures have been proposed as promising interventions to reduce racism and problematic policing. For example, Matsuda et al. (2020) recently outlined the 
potential extensions of mindfulness and acceptance and perspective taking training, all of which fall under the umbrella of Acceptance and Commitment Therapy (ACT), to reduce implicit bias. Whether these extensions produce meaningful explicit changes (e.g., reductions in use-of-force) is an unanswered empirical question, but behavior analysts have the technology to evaluate such claims. Moreover, the scaling of policy-wide ACT procedures across police departments may pose a barrier to the successful implementation and subsequent behavior change. Such endeavors may necessitate collaborative efforts with professionals who are adept at large-scale intervention dissemination and evaluation (e.g., public health) to successfully execute these pursuits.

\section{Conclusion}

The most common approach to improving use-of-force toward BIPOC by police officers has been to optimize use-of-force through executive policies, such as police use-of-force reform. BWCs and IBT have been two popular approaches under this umbrella, but research across both areas suggests future inquiry is needed before either can be ruled as efficacious. Behavior analysts can potentially contribute in meaningful ways, as the fundamental tenets within applied behavior analysis emphasize practitioners' pursuits to resolve real world, socially significant issues (Baer et al., 1968). Social pollution, like excessive use-of-force and biased policing, are clearly identifiable as socially significant issues.

We propose that behavior analytic technologies can be applied conceptually, experimentally, and therapeutically in many areas related to use-of-force to rectify current practices disproportionately impacting BIPOC. For example, a common issue across evaluations of BWC programs and IBT is that the behaviors targeted have been defined variably and outcomes are typically based on tangentially relevant variables (e.g., complaints filed or explicit responses on a test). Behavior analysts are skilled in defining and measuring behavior and could 
assist in the development of sound operational definitions of use-of-force and alternative behaviors, as well as accompanying measurement systems that more accurately and sensitively capture these behaviors. In turn, behavior analysts and other domains could use this foundation to produce more objective and technological language detailing contingencies for those specific behaviors. Once this has been accomplished, further evaluation surrounding the manipulation of those contingencies and the establishment of more effective contingencies can be undertaken.

Behavior analysts can also explore the boundary conditions under which currently applied use-of-force reform strategies are effective. For example, restrictive administrative policies regarding when force should be applied have sometimes been associated with fewer useof-force incidents (Terrill \& Paoline III, 2017), and some research suggests that BWCs can curtail the use-of-force during police encounters (e.g., Lum et al., 2019). Fortunately, Organizational Behavior Management (OBM) has already developed technologies that could translate well to the monitoring of these policies, as well as methods to pinpoint, analyze, and resolve performance problems associated with those policies. More broadly, behavior analysts have frequently evaluated the role of rules in behavior change programs (Schlinger \& Blakely, 1987) and have a robust knowledge of how antecedent and consequence variables differentially affect behavior. Rules governing use-of-force in police departments may therefore be evaluated to determine whether those rules effectively produce the behaviors targeted. Likewise, when shown to be ineffective, specific conditioning procedures might be contrived and applied to establish the effectiveness of BWCs. Specific contingencies can then be arranged and monitored to increase and decrease appropriate and inappropriate use-of-force, respectively. Potential treatment variations could include imposing a departmental reward structure for safe policing (Fridell, 2005), arranging civilian oversight committees (Engel et al., 2020), and improving the 
speed and consistency with which the arranged contingencies are applied (University of Chicago Law School - International Human Rights Clinic, 2020). Subsequent analyses of how these interventions impact perceptions of police legitimacy could then be undertaken.

We recognize that these pursuits may appear to be beyond the scope of practice for many behavior analysts, but we encourage readers to draw parallels between the importance of racially-biased policing and the goals of applied behavior analysis. Per Baer et al. (1968), "The label applied is not determined by the research procedures used but by the interest which society shows in the problems being studied" (p. 92). In this way, the appropriateness of the target is determined by the society in which that target occurs. The target of excessive use-of-force toward BIPOC is recognized by both the scientific community (e.g., Nix et al., 2017) and society at large (Pew Research Center, 2019) as a problematic issue within our communities that necessitates resolution. The successful eradication of pollutants like excessive use-of-force towards BIPOC warrants involvement and collaboration among many disciplines, including behavior analysis. The time to recognize that our field holds promise in making lasting, societal change in this area is now. 


\section{References}

Angelou, M. (1986). All God's Children Need Traveling Shoes. New York, NY: Vintage.

Ariel, B., Sutherland, A., Henstock, D., Young, J., Drover, P., Sykes, J., Megicks, S., \& Henderson, R. (2016a). Wearing body cameras increases assaults against officers and does not reduce police use of force: Results from a global multi-site experiment. European Journal of Criminology, 13(6), 744 - 755. https://doi.org/10.1177/1477370816643734

Ariel, B., Sutherland, A., Henstock, D., Young, J., Drover, P., Sykes, J., Megicks, S., \& Henderson, R. (2016b). Report: Increases in police use of force in the presence of bodyworn cameras are driven by officer discretion: A protocol-based subgroup analysis of ten randomized experiments. Journal of Experimental Criminology, 12(1), 444 - 463. https://doi.org/10.1007/s11292-016-9261-3

Ariel, B., Sutherland, A., Henstock, D., Young, J., Drover, P., Sykes, J., Megicks, S., \& Henderson, R. (2017). "Contagious accountability": A global multisite randomized controlled trial on the effect of police body-worn cameras on citizens' complaints against the police. Criminal Justice and Behavior, 44(2), 293 - 316. https://doi.org/10.1177/0093854816668218

Ariel, B., Sutherland, A., Henstock, D., Young, J., Drover, P., Sykes, J., Megicks, S., \& Henderson, R. (2018). Paradoxical effects of self-awareness of being observed: Testing the effect of police body-worn cameras on assaults and aggression against officers. Journal of Experimental Criminology, 14, 19 - 47. https://doi.org/10.1007/s11292-017$\underline{9311-5}$ 
Attard, B. (2010). Oversight of law enforcement is beneficial and needed - Both inside and out. Pace Law Review, 30(5). 1548 - 1561. Retrieved from https://digitalcommons.pace.edu/plr/vol30/iss5/12

Black, D. J. (1976). The Behavior of Law. New York: Academic Press.

Blanton, H., \& Jaccard, J. (2017). You can't assess the forest if you can't assess the trees: Psychometric challenges to measuring implicit bias in crowds. Psychological Inquiry, 28, 249-257. https://doi.org/10.1080/1047840X.2017.1373550

Booth, A., Scantlebury, A., Hughes-Morley, A., Mitchell, N., Wright, K., Scott, W., \& McDaid, C. (2017). Mental health training programmes for non-mental health trained professionals coming into contact with people with mental ill health: A systematic review of effectiveness. BMC Psychiatry, 17(1), 1-24. https://doi.org/10.1186/s12888-017-1356-5

Bosman, J., \& Smith, M. (2017, January 14). Excessive force is rife in Chicago, U.S. review finds. The New York Times, A1. Retrieved from http://www.nytimes.com/images/2017/01/14/nytfrontpage/scan.pdf

Braga, A. A., Barao, L., McDevitt, J., \& Zimmerman, G. (2018). The impact of body-worn cameras on complaints against officers and officer use of force incident reports: Preliminary evaluation findings. Boston, MA: Northeastern University Press.

Chapman, B. (2019, January). Body-worn cameras: What the evidence tells us. National Institute of Justice, 280. 1 - 5. Retrieved from https://www.ncjrs.gov/pdffiles1/nij/252035.pdf

Correll, J., Hudson, S. M., Guillermo, S., \& Ma, D. S. (2014). The police officer's dilemma: A decade of research on racial bias in the decision to shoot. Social and Personality Psychology Compass, 8(5), 201-213. https://doi.org/10.1111/spc3.12099 
Correll, J., Park, B., Judd, C. M., \& Wittenbrink, B. (2007). The influence of stereotypes on decisions to shoot. European Journal of Social Psychology, 37(6), 1102-1117. https://doi.org/10.1002/ejsp.450

Cubitt, T. I. C., Lesic, R., Myers, G. L., \& Corry, R. (2017). Body-worn video: A systematic review of the literature. Journal of Criminology, 50(3), 379 - 396. https://doi.org/10.1177/0004865816638909

Cunningham, W. A., Preacher, K. J., \& Banaji, M. R. (2001). Implicit attitude measurement: Consistency, stability, and convergent validity. Psychological Science, 12, 163-170. https://doi.org/10.1111/1467-9280.00328

DeGue, S., Fowler, K. A., \& Calkins, C. (2016). Deaths due to use of lethal force by law enforcement: Findings from the National Violent Death Reporting System, 17 U.S. States, 2009-2012. American Journal of Preventive Medicine, 51(5). S173 - S187. https://doi.org/10.1016/j.amepre.2016.08.027

DeHouwer, J. D. (2019). Implicit bias is behavior: A functional-cognitive perspective on implicit bias. Perspectives on Psychological Science, 14(5). 835 - 840. https://doi.org/10.1177/1745691619855638

Department of Justice Community Relations Services Toolkit for Policing. Understanding Bias: A Resource Guide. Retrieved from the Department of Justice Website: https://www.justice.gov/crs/file/836431/download

DiGennaro Reed, F. D., Erath, T. G., Brand, D., \& Novak, M. D. (2018). Video modeling during coaching and performance feedback. In A. Fischer, T. Collins, E. Dart, \& K. Radley (Eds.). Technology applications in school psychology consultation, supervision, and training (Chapter 3). New York, NY: Routledge. 
Duncan, B. L. (1976). Differential social perception and attribution of intergroup violence: Testing the lower limits of stereotyping of blacks. Journal of Personality and Social Psychology 34(4), 590-598. http://dx.doi.org.portal.lib.fit.edu/10.1037/00223514.34.4.590

Eberhardt, J. L., Goff, P. A., Purdie, V. J., \& Davies, P. G. (2004). Seeing black: Race, crime, and visual processing. Journal of Personality and Social Psychology, 87(6), 876-893. https://doi.org/10.1037/0022-3514.87.6.876

Ellis, T., Smith, P., \& Jenkins, C. (2015). Evaluation of the introduction of personal issue body worn video cameras (Operation Hyperion) on the Isle of Wight: Final Report to Hampshire Police (2015). Portsmouth, UK; University of Portsmouth

Engel, R. S., McManus, H. D., \& Isaza, G. T. (2020). Moving beyond "best practice”: Experiences in police reform and a call for evidence to reduce officer-involved shootings. The Annals of the American Academy, 687, 146-165. https://doi.org/10.1177/0002716219889328

Forscher, P. S., Lai, C. K., Axt, J. R., Ebersole, C. R., Herman, M., Devine, P. G., \& Nosek, B. A. (2019). A meta-analysis of procedures to change implicit measures. Journal of Personality and Social Psychology, 117(3), 522. http://dx.doi.org/10.1037/pspa0000160

Fridell, L. A. (2005). Use-of-force policy, policy enforcement, and training. In J.A. Ederheimer and L.A. Fridell (Eds.), Chief concerns: Exploring the challenges of police use of force. Police Executive Research Forum. Retrieved from https://www.policeforum.org/assets/chiefconcernsuseofforce.pdf 
Gaub, J. E., Choate, D. E., Todak, N., Katz, C. M., \& White, M. D. (2016). Officer perceptions of body-worn cameras before and after deployment: A study of three departments. Police Quarterly, 19(3). 275 - 302. https://doi.org/10.1177/1098611116653398

Gawronski, B. (2019). Six lessons for a cogent science of implicit bias and its criticism. Perspectives on Psychological Science, 14(4), 574-595. https://pubmed.ncbi.nlm.nih.gov/31181174/

Goodall, M. (2007). Guidance for the police use of body-worn video devices: Police and crime standards directorate. London, UK: Home Office. http://library.college.police.uk/docs/homeoffice/guidance-body-worn-devices.pdf

Greenwald, A. G., McGhee, D. E., \& Schwartz, J. L. K. (1998). Measuring individual differences in implicit cognition: The implicit association test. Journal of Personality and Social Psychology, 74(6), 1464-1480. https://doi.org/10.1037/0022-3514.74.6.1464

Grossmith, L., Owens, C., Finn, W., Mann, D., Davies, T., Baika, L. (2015). Police, camera, evidence: London's cluster randomized controlled trial of body worn video. London: College of Policing Limited and the Mayor's Office for Policing and Crime (MOPAC). https://whatworks.college.police.uk/Research/Documents/Police_Camera_Evidence.pdf

Hedberg, E. C., Katz, C. M., \& Choate, D. E. (2017). Body-worn cameras and citizen interactions with police officers: Estimating plausible effects given varying compliance levels. Justice Quarterly, 34(4), 627 - 651. https://doi.org/10.1080/07418825.2016.1198825

Hehman, E., Calanchini, J., Flake, J. K., \& Leitner, J. B. (2019). Establishing construct validity evidence for regional measures of explicit and implicit racial bias. Journal of 
Experimental Psychology, 148(6), 1022-1040.

https://pubmed.ncbi.nlm.nih.gov/31180716/

Hickman, M. J., \& Poore, J. E. (2016). National data on citizen complaints about police use of force: Data quality concerns and the potential (mis)use of statistical evidence to address police agency conduct. Criminal Justice Policy Review, 27(5), 455 - 479.

https://nij.ojp.gov/library/publications/national-data-citizen-complaints-about-police-useforce-data-quality-concerns

James, L. (2018). The stability of implicit racial bias in police officers. Police Quarterly, 21(1), 30-52. https://doi.org/10.1177/1098611117732974

Jennings, W. G., Fridell, L. A., Lunch, M., Jetelina, K. K., \& Reingle Gonzalez, J. M. (2017). A quasi-experimental evaluation of the effects of police body-worn cameras (BWCs) on response-to-resistance in a large metropolitan police department. Deviant Behavior, 38(11). 1332 - 1339. http://dx.doi.org/10.1080/01639625.2016.1248711

Katz, C. M. Choate, D. E., Ready, J. R., \& Nuňo, L. (2015). Evaluating the impact of officer body worn cameras in the Phoenix police department. Phoenix: Center for Violence Prevention and Community Safety, Arizona State University. https://publicservice.asu.edu/sites/default/files/ppd_spi_feb_20_2015_final.pdf

Lafayette Group. (2015). Major cities chiefs and major county sheriffs: Technology needs - body worn cameras. https://assets.bwbx.io/documents/users/iqiWHBFdfxIU/rvnT.EAJQwK4/v0

Legewie, J. (2016). Racial profiling and use of force in police stops: How local events trigger periods of increased discrimination. American Journal of Sociology, 122(2), 379 - 424. Retrieved from https://www.journals.uchicago.edu/doi/abs/10.1086/687518 
Lum, C., Koper, C., Merola, L, Scherer, \& Reioux, A. (2015). Existing and ongoing body worn camera research: Knowledge gaps and opportunities. Report for the Laura and John Arnold Foundation. Fairfax, VA: Center for Evidence-Based Crime Policy, George Mason University. https://cebcp.org/wpcontent/technology/BodyWornCameraResearch.pdf

Lum, C., \& Nagin, D. S. (2017). Reinventing american policing. Crime and Justice, 46(1), 339 393. Retrieved from https://www.journals.uchicago.edu/doi/pdfplus/10.1086/688462

Lum, C., Stoltz, M., Koper, C. S., \& Scherer, J. A. (2019). Research on body-worn cameras: What we know, what we need to know. Criminology and Public Policy, 18, 93 - 118. https://doi.org/10.1111/1745-9133.12412

Luiselli, J. K. (2008). Antecedent (preventative) intervention. In J. Luiselli, D. Russo, W. Christian, \& S. Wilczynski (Ed.), Effective practices for children with autism: Educational and behavioral support interventions that work (pp. 393 - 412). Oxford University Press

Marcus, N. C. (2016). From Edward to Eric Garner and beyond: The importance of constitutional limits on lethal use of force in police reform. Duke Journal of Constitutional Law and Public Policy, 12(1), 53 - 106. Retrieved from https://scholarship.law.duke.edu/djclpp/vol12/iss1/2/

Matsuda, K., Garcia, Y., Catagnus, R., \& Brandt, J. A. (2020). Can behavior analysis help us understand and reduce racism? A review of the current literature. Behavior Analysis in Practice, 13, 336 - 347. https://doi.org/10.1007/s40617-020-00411-4

Mears, D. P., Militonette, O. C., Stewart, E. A., \& Warren, P. Y. (2017). Thinking fast, not slow: How cognitive biases may contribute to racial disparities in use of force in police-citizen 
encounters. Journal of Criminal Justice, 53. 12 - 24.

http://dx.doi.org/10.1016/j.jcrimjus.2017.09.001

Mekawi, Y. \& Bresin, K. (2015). Is the evidence from racial bias shooting task studies a smoking gun? Results from a meta-analysis. Journal of Experimental Social Psychology, 61, 120-130. https://doi.org/10.1016/j.jesp.2015.08.002

Michael, J. (1993). Establishing operations. The Behavior Analyst, 16(2), 191 - 206. https://psycnet.apa.org/doi/10.1007/BF03392623

Miller, L, Toliver, J., \& Police Executive Research Forum. (2014). Implementing a body-worn camera program: Recommendations and lessons learned. Washington, DC: Office of Community Oriented Policing Services. Retrieved from https://www.justice.gov/iso/opa/resources/472014912134715246869.pdf

Mitchell, G. (2018). An implicit bias primer. Virginia Journal of Social Policy \& the Law, 25, 27-59. Retrieved from http://vjspl.org/wp-content/uploads/2019/02/Mitchell-25.1formatted-KMM-updated.pdf

Morrozoff Luna, A. (2005). Introduction. In J.A. Ederheimer and L.A. Fridell (Eds.), Chief concerns: Exploring the challenges of police use of force. Police Executive Research Forum. Retrieved from https://www.policeforum.org/assets/chiefconcernsuseofforce.pdf

Murphy, J. R. (2019). Is it recording? - Racial bias, police accountability, and the body-worn camera activation policies of the ten largest metropolitan police departments in the USA. Columbia Journal of Race and Law, 9(1), 141 - 190. Retrieved from https://papers.ssrn.com/sol3/papers.cfm?abstract_id=3369579 
Nix, J., Cambell, B. A., Byers, E. H., Alpert, G. P. (2017). A bird's-eye view of civilians killed by police in 2015: Further evidence of implicit bias. Criminology and Public Policy, 16(1), 309-340. https://doi.org/10.1111/1745-9133.12269

Oswald, F. L., Mitchell, G., Blanton, H., Jaccard, J., \& Tetlock, P. E. (2013). Predicting ethnic and racial discrimination: a meta-analysis of IAT criterion studies. Journal of Personality and Social Psychology, 105(2), 171. http://dx.doi.org/10.1037/a0032734

Palmer, D. C. (2009). Response strength and the concept of the repertoire. European Journal of Behavior Analysis, 10(1), 49-60. https://doi.org/10.1080/15021149.2009.11434308

Parsons, M. B., Rollyson, J. H., \& Reid, D. H. (2012). Evidence-based staff training: A guide for practitioners. Behavior Analysis in Practice, 5(2), 2 - 11. https://dx.doi.org/10.1007\%2FBF03391819

Pew Research Center. (2019, April 2019). Race in America 2019 [Report]. https://www.pewsocialtrends.org/wp-content/uploads/sites/3/2019/04/Racereport_updated-4.29.19.pdf

Reid, D. H., Rotholz, D. A., Parsons, M. B., Morris, L., Braswell, B. A., Green, C. W., \& Schell, R. M. (2003). Training human service supervisors in aspects of positive behavior support: Evaluation of a state-wide, performance-based program. Journal of Positive Behavior Interventions, 5(1), 35 - 46. https://psycnet.apa.org/doi/10.1177/10983007030050010601

Rodriguez, B. J., Loman, S. L., \& Horner, R. H. (2009). A preliminary analysis of the effects of coaching feedback on teacher implementation fidelity of First Step to Success. Behavior Analysis in Practice, 2(2), 11 - 21. https://doi.org/10.1007/bf03391744

Sagar, H. A., \& Schofield, J. W. (1980). Racial and behavioral cues in black and white children's perceptions of ambiguously aggressive acts. Journal of Personality and Social 
Psychology 39(4), 590-598. http://dx.doi.org.portal.lib.fit.edu/10.1037/00223514.39.4.590

Schlinger, H., \& Blakely, E. (1987). Function-altering effects of contingency-specifying stimuli. The Behavior Analyst, 10(1), 41 - 45. https://doi.org/10.1007/BF03392405

Seitz, S. (2011, June 17). Prejudices are bad for everybody, study finds. University of Massachusetts Lowell. Retrieved from https://www.uml.edu/news/stories/201011/prejudice_affects_health.aspx

Skinner, B. F. (1953). Science and human behavior. New York, NY: Macmillan.

Skinner, B. F. (1969). Contingencies of reinforcement: A theoretical analysis. Michigan: Appleton-Century-Crofts.

Smith, J. (2017, March 10). Sessions doesn't want to investigate police. Here's why we need to. The Washington Post, B4. Retrieved from https://www.washingtonpost.com/posteverything/wp/2017/03/10/sessions-doesnt-want$\underline{\text { to-investigate-police-heres-why-we-need-to/ }}$

Spencer, K. B., Charbonneau, A. K., Glaser, J. (2016). Implicit bias and policing. Social and Personality Psychology Compass, 10(1), 50 - 63. https://doi.org/10.1111/spc3.12210

Terrill, W., \& Paoline III, E. A. (2017). Police use of less lethal force: Does administrative policy matter? Justice Quarterly, 34(2). 193 - 216. https://doi.org/10.1080/07418825.2016.1147593

University of Chicago Law School - International Human Rights Clinic (2020). Deadly discretion: The failure of police use of force policies to meet fundamental international human rights law and standards. International Human Rights Clinic, 14. Retrieved from https://chicagounbound.uchicago.edu/ihrc/14 
Yokum, D., Ravishankar, A., \& Coppock, A. (2019). A randomized control trial evaluating the effects of police body-worn cameras. Proceedings of the National Academy of Sciences, 116(21). 10329 - 20332. www.pnas.org/cgi/doi/10.1073/pnas.1814773116 